\section{Vidas em fuga: juventude e justiça criminal}

GOFFMAN, Alice. On the run: fugitive life in an American city. Chicago, University of Chicago Press, 2014. 288 pp.

\section{Herbert Rodrigues}

Durante as seis primeiras décadas do século XX, a população carcerária nos Estados Unidos se manteve relativamente estável: uma pessoa adulta presa para cada mil habitantes. Na década de 1970, o número começou a crescer e simplesmente disparou nas três décadas seguintes. Logo, nos anos de 2000 o número de encarcerados chegou a taxas inéditas na história do país: uma a cada 107 pessoas da população adulta estava atrás das grades.

Atualmente, os Estados Unidos prendem de cinco a nove vezes mais do que as naçóes europeias ocidentais, apresentando-se significativamente à frente de Rússia, China e Brasil. Cerca de 3\% da população adulta norte-americana está envolvida em algum regime penal: 2,2 milhóes de pessoas presas e outros 4,8 milhóes sob supervisão penal. $\mathrm{Na}$ história recente, apenas os campos de trabalho forçado na antiga União Soviética sob o regime de Stalin chegaram perto desse nível de aprisionamento.

Todos esses números são oficiais e fornecidos pelo Departamento de Justiça dos Estados Unidos. $\mathrm{E}$, apesar de alarmantes, não necessariamente chamam atenção das camadas médias da população. Muitos não os notam por uma única razão: a distribuição da população presa é desproporcional entre brancos e negros, ricos e pobres.

Nos Estados Unidos, os negros representam $13 \%$ do total da população do país, mas correspondem a $37 \%$ da população carcerária; entre os jovens negros, um a cada nove está preso, ou seja, representam a maioria absoluta. Estima-se que aproximadamente $60 \%$ dos jovens negros que não concluíram o ensino médio irão para a cadeia por volta dos trinta anos de idade.

Esse é o contexto social do livro On the run: fugitive life in an American city, de Alice Goffman. $\mathrm{O}$ objetivo da obra não reside somente em analisar a chamada "guerra ao crime" e o fenômeno de encarceramento em massa nos Estados Unidos nas últimas décadas: traduz-se em empreender um estudo a contrapelo das consequências e dos impactos do sistema de justiça criminal na vida de jovens negros pobres moradores dos bairros segregados das cidades norte-americanas. O medo da captura e do confinamento compromete relaçóes básicas do cotidiano - trabalho, estudo, família, relacionamentos amorosos e amizades - e gera uma comunidade inteira de indivíduos que constantemente cria estratégias para fugir da polícia.

O título e o subtítulo do livro mostram-se simples e objetivos: Em fuga: vida fugitiva em uma cidade norte-americana, em tradução literal. A obra resulta da tese de doutorado defendida pela autora no departamento de sociologia da Princeton University em 2010. Consiste numa pesquisa etnográfica de total imersão no campo, realizada de perto e de dentro, ao longo de seis anos num bairro pobre de população majoritariamente negra na cidade da Filadélfia, na Pensilvânia. Nas palavras da autora: "meu projeto pode ser enquadrado como um olhar on-the-ground sobre o encarceramento em massa e seus sistemas de policiamento e de vigilância” (p. 251).

A narrativa de Goffman, apesar de algumas repetiçóes de cenas e de imagens, envolve e leva o leitor ao interior do universo pesquisado. Os embates teóricos enfrentados pela autora buscam transformar problemas sociais em problemas de pesquisa. Em primeiro lugar, a autora adota a perspectiva dos sujeitos para produzir uma narrativa que considere os impactos do encarceramento em massa nas relaçóes sociais e nas práticas de policiamento e de vigilância dos jovens negros.

Em segundo lugar, para compreender as relaçóes entre os atores, os arranjos institucionais e as dinâmicas das estratégias de sobrevivência, recorre-se à descrição etnográfica detalhada de cenas do dia a dia. Por fim, a autora debate diretamente com os operadores da justiça criminal responsáveis pela gestão dos controles sociais dessa população e, simultaneamente, dialoga com os recentes trabalhos sobre o estado penal e punitivo, o fenômeno do "hiperpoliciamento", e engrossa o coro da luta pela reforma do sistema de justiça nos Estados Unidos.

A autora utiliza nomes fictícios tanto para as pessoas quanto para os lugares, e altera algumas datas de eventos; recurso que, segundo ela, desca- 
racteriza a individualização das informaçóes e garante a segurança das pessoas. Assim, Goffman nos leva, primeiramente, ao universo dos jovens $\mathrm{Chu}$ ck, Mike, Reggie e alguns vizinhos, moradores da 6th Street, num determinado bairro segregado da Filadélfia. Os rapazes são os condutores da narrativa do início ao fim. Conforme os capítulos vão se desenvolvendo, outras personagens e situações entram na história para ampliar o universo de relaçóes - principalmente mães e namoradas -, mas o foco do livro assenta-se nas estratégias de sobrevivência e de fuga dos rapazes da 6th Street.

Goffman organizou o livro em sete capítulos, além da introdução e da conclusão. $\mathrm{O}$ trabalho possui ainda prólogo, epílogo e apêndice metodológico. Os capítulos náo estão dispostos de modo cronológico, e sim a partir de cenas etnográficas que descrevem as açóes dos diversos personagens da trama e as experiências vividas durante a pesquisa participante.

Resumidamente, o capítulo 1 apresenta os jovens da 6th Street e o alcance do emaranhado do sistema legal na vida das pessoas para além do encarceramento. O capítulo 2 apresenta o processo de transmissão intergeracional de conhecimento dos mais velhos aos mais jovens na tentativa de evitar qualquer contato com autoridades legais, ao qual a autora denomina de "arte de fugir".

O capítulo 3 descreve o desespero de ter a polícia repentinamente batendo à porta e invadindo a casa para interrogar as pessoas. A autora narra experiências impressionantes, do ponto de vista da tensão e da brutalidade, e relata com detalhes alguns terrores sofridos por ela. Por exemplo, o momento em que a polícia invadiu o apartamento onde dormia à procura de um rapaz: os policiais a imobilizaram com chave de braço, pressionaram seu rosto contra o chão e exigiram que ela falasse onde estava a pessoa procurada. Talvez esse seja o capítulo mais duro do livro, por envolver jogos de relaçóes triangulares entre a polícia, os jovens e as famílias.

O capítulo 4 discute a incursão dos problemas legais na vida pessoal. Há um clima generalizado de medo e desconfiança que perpassa por todas as relaçóes dos indivíduos: não é necessário estar preso para viver contido. Fato que ocorre porque está em expansão na sociedade norte-americana (e também em outras) aquilo que Loïc Wacquant (2003) denomina de "contenção punitiva" - mecanismos de gestão de uma população potencialmente perigosa. O crescimento desse sistema punitivo, que vai além dos muros das prisóes, originou a figura do indivíduo em fuga.

O capítulo 5 aborda a vida social de jovens criminalizados. As novas tecnologias e ferramentas de controle social permitem acompanhar em detalhes os passos das pessoas e, qualquer falha cometida por exemplo, uma multa de trânsito - pode gerar rapidamente um mandado de prisão. Com isso, essas pessoas evitam a todo custo qualquer contato com a esfera legal, chegando ao extremo de não comparecer a funerais, ao nascimento dos filhos, de não buscar assistência médica ou, ainda, qualquer tipo de trabalho formal pela simples possibilidade tanto de seus nomes serem verificados pela polícia nesses lugares quanto de serem levadas de volta à prisão.

O capítulo 6 descreve a criação de mercado informal de mercadorias, proteçôes e privilégios. Essa economia subterrânea é estrategicamente essencial para a manutenção da vida em fuga. Nesse capítulo, podemos perceber claramente os impactos do sistema de justiça criminal na vida cotidiana dos jovens.

O capítulo 7 adiciona na trama as chamadas pessoas "limpas". Ser considerado "limpo" (ter emprego formal, carteira de habilitação e não possuir antecedentes criminais) funciona como mecanismo de distinção social entre pessoas pobres que vivem no mesmo bairro. Talvez esse seja o capítulo mais problemático do livro. Ao traduzir categorias nativas de "limpos" e "sujos" em categorias de análise, a autora reforça a visão binária e estereotipada sobre essas pessoas. Em uma etnografia urbana é preciso reconhecer a complexidade das relaçóes, identificar as práticas socialmente enraizadas que geram tais dicotomias, e não tomar a superfície discursiva como fato e aceitar a taxonomia nativa como forma de ordenamento da realidade.

Por fim, a autora conclui a obra com a ideia de "comunidade fugitiva": na suposta terra das oportunidades emerge a figura do indivíduo em fuga. Em fuga não somente da polícia, mas de qualquer contato com os agentes legais que possam representar a possibilidade - ainda que remota de ser preso. 
On the run explora as consequências brutais do estado punitivo. Há episódios tão absurdos que parecem sair de algum filme de Quentin Tarantino, Martin Scorsese ou Abel Ferrara. Diversas tramas envolvendo agentes do sistema penitenciário, como a troca de favores e os privilégios por sexo oral, lembram os livros de James Ellroy ou de Chuck Palahniuk sobre o submundo dos Estados Unidos. Há material suficientemente surreal retirado da experiência etnográfica que torna a realidade mais estranha que a ficção, como a venda de urina "limpa" (sem vestígios de álcool ou drogas) para testes na justiça, ou a descrição de uma cirurgia em um jovem baleado realizada em plena mesa da cozinha.

$\mathrm{O}$ apêndice apresenta questóes metodológicas da pesquisa participante, mas a autora também esclarece em detalhes alguns eventos relatados nos capítulos do livro: descreve percursos, acidentes e acasos que a levaram ao encontro daquelas pessoas; os incidentes que desencadearam conflitos e disputas entre os jovens no bairro; reflexóes pessoais sobre o uso do corpo no trabalho de campo; o trânsito entre universos simbólicos distintos; a estranheza em retornar ao convívio de pessoas da mesma origem social de classe média branca; seus medos e suas afliçóes em campo; e, ainda, questionamentos acerca de questóes de gênero e sexualidade.

Para as pessoas interessadas em saber sobre os bastidores da pesquisa e a conduta da pesquisadora em campo - além de entender como uma garota branca de classe média alta, estudante de uma das mais prestigiadas universidades dos Estados Unidos, conseguiu se aproximar daquelas pessoas, ser aceita no convívio diário das famílias, conquistar a confiança dos rapazes com problemas na justiça e viver num bairro violento e segregado - o apêndice configura-se precioso e pode ser lido tanto no fim como no início da leitura, sem prejuízo de arruinar eventuais surpresas da narrativa.

O apêndice metodológico esclarece o processo de realização da pesquisa até o formato final do livro. Entretanto, um fato se destaca: o relato do assassinato do jovem com quem ela conviveu durante todo o tempo de pesquisa mostra-se algo sem precedentes na escrita acadêmica contemporânea. São raras as ocasióes nas quais podemos ler um texto táo carregado de afeto como o escrito por
Alice Goffman nos últimos parágrafos do livro. Há implicada união entre memória e testemunho, relato etnográfico e análise sociológica crítica, também de indignação diante da perda de um amigo e o florescimento de sentimentos como ódio e vingança.

Em On the run, Alice Goffman honra a tradição das grandes etnografias urbanas publicadas nos Estados Unidos nas primeiras décadas do século XX, especialmente as realizadas pela Escola Sociológica de Chicago e no âmbito do interacionismo simbólico, incluindo os trabalhos de seu pai biológico, o renomado sociólogo Erving Goffman, que faleceu no mesmo ano em que a filha nasceu. A principal diferença é que a autora não se mostra preocupada em solucionar os problemas da suposta desorganização social da cidade. Ao contrário, aponta os parâmetros de inteligibilidade de um grupo social que estrategicamente sobrevive nas fronteiras entre o legal e o ilegal, questionando as consequências do encarceramento em massa na vida desses jovens.

Podemos dizer que, de um lado, a autora se aproxima do interacionismo simbólico ao interpretar os significados das situaçóes socialmente construídas. Segundo essa abordagem, os atores sociais constroem seus papéis de acordo com as circunstâncias que percebem em cada situação na medida em que esses papéis são negociados e socialmente definidos. O que Alice Goffman faz, de modo exemplar, é descrever, por vezes literalmente, os processos dinâmicos, contínuos e estratégicos pelos quais os indivíduos dão significado às açôes, mesmo que de maneira provisória, pois no dia seguinte as estratégias precisam ser reconstruídas.

De outro lado, On the run poderia causar a impressão de ser um trabalho meramente descritivo e supostamente desprovido de teoria e interpretação sociológica; mas essa percepção não é exata. A autora articula muito bem a descrição etnográfica com as referências da teoria do desvio e do controle social, cujos representantes contemporâneos, David Garland, Loïc Wacquant e Howard Becker, são seus principais interlocutores.

Para Howard Becker (2008), a delinquência e o desvio são rótulos socialmente construídos utilizados para identificar indivíduos que transgrediram linhas prescritas do comportamento normativo. 
Identificação realizada por meio de conjunto de forças sociais criadoras de normas e de regras. $\mathrm{O}$ autor ressalta que "o desvio náo é uma qualidade simples, presente em alguns tipos de comportamento e ausente em outros. É antes o produto de um processo que envolve reaçóes de outras pessoas ao comportamento" (Becker, 2008, p. 26).

Além disso, diferentemente do que costumamos encontrar nos trabalhos de criminologistas (que majoritariamente analisam a violência por meio de estatísticas), os sujeitos da pesquisa de Alice Goffman são de carne e osso, possuem nome, cor, idade e endereço. E mais: a autora descreve as estruturas de poder e de controle sobre a população socialmente vulnerável e as interconexôes entre o Estado, o sistema de justiça e o policiamento voltadas para o controle dos jovens negros. Com isso, podemos dizer que a autora avança em relação ao interacionismo e à teoria do desvio e do controle social, ampliando o campo de debate sobre o avanço do sistema punitivo de justiça e seus efeitos práticos na vida das pessoas.

Outro aspecto interessante do livro (talvez o menos importante) reside na controvérsia acerca de algumas passagens, gerada, segundo inferi, pela crítica apressada do professor Steven Lubet, ${ }^{1}$ jurista e professor de direito da Northwestern University, na região de Chicago. $\mathrm{O}$ ponto central da acusação de Lubet assenta-se no fato de que, durante a pesquisa, Goffman sai à procura dos assassinos de Chuck conduzindo um veículo na companhia de jovens armados na intenção de vingar a morte do amigo.

$\mathrm{O}$ argumento da acusação baseia-se nas Conspiracy Laws (Leis de Conspiração), ${ }^{2}$ de acordo com as quais alguém que conhece um traficante de drogas e o ajuda a fugir da polícia potencialmente pode ser considerada criminosa. A questão é que Goffman se junta aos jovens da 6th Street para realizar trabalho acadêmico por meio de pesquisa participante, não para cometer crimes. E a autora cumpre muito bem seu dever de etnógrafa ao descrever o que tinha de descrever.

A denúncia do professor Lubet, se levada a cabo, poderia abrir precedente perigoso de restriçáo ao exercício da profissão de sociólogo. No entanto, grande parte da comunidade acadêmica dos Estados Unidos reagiu em apoio irrestrito ao livro e à conduta da pesquisadora. Sorte não apenas de Goffman, mas dos futuros etnógrafos que queiram se engajar num trabalho tão difícil e sensível (além de raramente valorizado) que é a pesquisa participante.

A resposta de Goffman mostra-se exemplar. ${ }^{3}$ Em texto de apenas quatro páginas, a autora esclarece todas as acusaçóes, explica os mal-entendidos do jurista e, por fim, ao citar "De que lado estamos", de Howard Becker (1977), salienta que a crítica de Lubet baseia-se na ideia elitista de hierarquia da credibilidade, na qual existe um grupo no topo do conhecimento que acredita possuir o direito de definir as coisas de acordo com o que pensa. Sáo pessoas que utilizam o poder e a autoridade para retirar credibilidade das pessoas que se encontram na base da pirâmide social. Em On the run, a autora busca intencionalmente inverter essa lógica ao dar voz e protagonismo às pessoas que se encontram no limbo da legalidade e em situação de fuga.

As críticas de Lubert são superficiais. Mas o problema reside justamente nesse ponto. Por serem rasos, os questionamentos atingem mais facilmente o público socializado no imediatismo simplório da informaçáo em tempos de redes sociais. No entanto, há uma vantagem: com a mesma velocidade na qual as coisas acontecem, elas desaparecem, mas não sem antes fazerem estragos. Daí outra qualidade do livro: passar ileso pela polêmica e sair fortalecido. O efeito colateral gerou um aumento nas vendas e a pluralização de resenhas favoráveis ao trabalho. As críticas positivas não apenas apoiam a autora, mas destacam a relevância do tema, a qualidade do texto e a capacidade de imersão no campo.

Algumas conclusões de Goffman são conhecidas, apesar da ausência de uma reação mais contundente por parte da sociedade norte-americana. Em primeiro lugar, a autora aponta para a importância da educaçáo como condição estrutural de mobilidade social. Em segundo, a importância de uma base familiar sólida, capaz de manter os filhos afastados dos problemas com a justiça. Mesmo as crianças e os adolescentes mais pobres podem ter vidas bem-sucedidas, desde que não saiam da escola para trabalhar ainda muito jovens, ou mesmo se envolvam em pequenos atos ilícitos e/ou com tráfico de drogas. Em terceiro lugar, a experiência no sistema de justiça e prisional mostra-se brutalizante e ineficaz 
em termos de reabilitação, ressocialização ou mesmo dissuasão para outros atos ilícitos. E, por fim, o resultado do encarceramento em massa representa a perpetuação das desigualdades raciais e sociais, a ampliação do estigma, do estado policialesco, da rede de controle social e dos pânicos morais.

Torço para que o livro seja rapidamente traduzido e publicado em português. A obra de Alice Goffman merece ser lida e discutida por cientistas sociais, estudiosos da violência, da criminologia, das relaçóes raciais, por urbanistas, por pesquisadores preocupados com a desigualdade social, a juventude e o fenômeno do encarceramento em massa. On the run é um livro para estudantes, acadêmicos, operadores do direito, gestores públicos, assistentes sociais e demais interessados em compreender a produção e reprodução da desigualdade de acesso aos direitos sociais fundamentais que atinge a população mais vulnerável da sociedade. Certamente, essa obra contribuirá para adensar o debate acadêmico nacional em torno desses temas.

Numa época sombria, em que parte considerável da sociedade brasileira prefere colocar adolescentes em conflito com a lei na cadeia e legitimar o fechamento de escolas, o universo retratado em $O n$ the run deslinda o cenário de como pode ser a vida de jovens fora da escola e sem apoio da família, da sociedade e do Estado: o desfecho não poderá ser outro que não a morte violenta, a prisão ou a vida em fuga.

\section{Notas}

1 Disponível em newramblerreview.com/book-reviews/ law/ethics-on-the-run, consultado em 8/8/2015.

2 No Brasil, por exemplo, não existe o crime de conspiração. Aqui, juridicamente utiliza-se a noção de "formação de quadrilha ou bando" a fim de cometer crimes.

3 Disponível em www.ssc.wisc.edu/soc/faculty/docs/ goffman/A\%20Reply\%20to\%20Professor\%20Lubet.pdf, consultado em 8/8/2015.

\section{BIBLIOGRAFIA}

BECKER, Howard. (1977), Uma teoria da ação coletiva. Rio de Janeiro, Zahar.

(2008), Outsiders: estudos de sociologia do desvio. Rio de Janeiro, Zahar.

WACQUANT, Loïc. (2003), Punir os pobres: a nova gestão da miséria nos Estados Unidos. Rio de Janeiro, Revan.

\section{HERBERT RODRIGUES é doutor em Sociologia pela Universidade de Sáo Paulo (USP). E pesquisador do Núcleo de Estudos da Violência da Universidade de Sáo Paulo (NEV-USP). E-mail: herb@usp.br}

DOI: $10.17666 / 329313 / 2017$ 